\title{
The Application of an Expressive Arts Activity for the very First Session of Training of Personal and Professional Development of Cognitive-Behavioural Clinical Psychologists: Cognitive Content as Proxy Data to Study Core Beliefs
}

\author{
Rosangela Bertelli \\ Universidade de Trás-os-Montes e Alto Douro \\ Escola de Ciências Humanas e Sociais \\ Quinta de Prados, 5001-801. Vila Real, Portugal
}

\begin{abstract}
Cognitive-behavioural psychotherapies are evidence based interventions which are carried out thorough the examination of proxies such as automatic thoughts which could be thought of as memories of the past pointing towards one's core beliefs. Expressive arts activities were applied in the first session of training of cognitivebehavioural personal and professional development of 67 master's degree students in clinical psychology. The students were instructed to colouring outlines of images and at the same time quietly watch their streaming of thoughts without making judgements or replying to those thoughts. At the end of the expressive arts activity they had the opportunity to write down and report on their mental experiences. Such reports were filled with proxies and were properly examined. Results revealed contents concerning recollections about family and longing for family, responsibilities and expectations tilted towards family, and very few instances of consciousness and comprehending (“...I allowed myself to follow those running automatic thoughts..."). Considering these results, in order for the prediction that the coming of this (humankind) geological force's self-awareness to come true it would require from humankind a deep understanding of nature, including an extremely sharp and strongly felt selfunderstanding, and the transcendence of thought itself.
\end{abstract}

Keywords: Proxy Data, Core Beliefs, Cognitive-Behavioural Clinical Psychologists, Expressive Arts

\section{INTRODUCTION}

Palaeoclimatology is the study of the climate of past ages and such study aims to achieve an interpretation of palaeoclimate. On June $18^{\text {th }} 2019$, the keynote speech to the International Meeting on Palaeoclimate [1] delivered by the astrobiologist David Grinspoon ended with the following keynote: "Have cognitive processes become planetary processes?"

What does that question mean? Does it mean that Humankind became the planet's thought, the planet's conscious awareness, the planet's self-aware cognition, the planet's transcendence of thought, or actually the planet's consciousness? [2]

\section{Palaeontology, palaeoclimatology, and proxies}

The word Palaeo derived from the Greek word $\pi \alpha \lambda \alpha$ ió $\varsigma$ or palaios means old, very old, prehistoric, very early, or primitive. Palaeontology makes reference to the earth science that studies fossil organisms and pertained remains $[3,4,5,6]$. Palaeoclimatology is carried out through the examination of imprints or proxies, that is, impressions produced by pressure or printing, which were created by the climates of past eras. 
Proxy data are collected from natural registers of climatic variability such as fossils, sediments and even historical registers [7, 8, 9]. Proxies could be thought of as memories of the past, of past ages, that is, what was/used to be, and such memories give scientists worthful insights into the changes in vegetation, climate, and disturbances caused by the interaction between diverse organisms (including, and for the most part, humankind) and their physical environments over a long period of geological time or epochs.

\section{Climate and thought}

Climate seems to be a reaction, the planet's reaction, to the movement of the atmosphere, to the changing of a particular environment or surrounding influences. Such reaction exhibits a global restless, uneasy moving pattern, ceaselessly in motion that sets off, for instance, volcano eruptions, earthquakes, and changes in sea level. In a metaphorical manner, thought seems to be a reaction, the brain's reaction, to the movement of memory, to the changing of circumstances or surrounding influences. The brain seems to display the same restlessness, uneasiness and an uninterrupted motion, just like the climate, and thought sets off, for instance, the sudden occurrence of a fierce discharge of thoughts, corresponding feelings and behaviours.

Articulating the concept of thought in terms that it would denote the concept of climate is not such an original perception. For instance, Buddha Gotama, Jiddu Krishnamurti, and more recently the cognitive-behavioural model of learning all do the same in a more or less crystalline presentation $[10,11]$. Climate and thought are both reactions that may give rise to confusion and disarray.

\section{Expressive arts}

The Palaeolithic rock art offers palaeoclimatologists valuable proxies, that is, registers, evidence, witnesses or climate markers. Art depicts, gives a description, or makes a portrait of changes, perceived changes, cycles of main climatic changes, environmental modifications and simultaneously environment-organisms interactions and adaptations.

Rock art tends to be found in remote, very unlikely, inaccessible caves, in sparsely populated areas, and in high-altitude caves located in places that contain little other evidence of human dwelling. Cave art motifs may include small and large animals, human figures and silhouette, isolated or in small groups, warriors, hunters, horsemen, boats, the human world, for instance, objects, daily life, caravans, decorated hand stencils, and schematic anthropomorphic figures $[12,13]$. Rock art, cave art are expressive arts characterized by the expression of knowledge tending to communicate information about the past or one's own memories of past events (recent past or distant past).

\section{Core beliefs}

Human beings seem to be grounded on their past, on their knowledge that was built, formed or accumulated steadily on their minds. As a consequence, human beings' thoughts are based on the past, on the known, on the memories that have been sculpted on their brains, and with which human beings identify. Accumulated knowledge creates a motion, a movement of thought, which is nothing but a retrospective on one's life events at a given place and time, the corresponding cognitive evaluations made at that particular place and time, and those consequent emotions and behaviours [11].

Core beliefs or schemas are any cognitive content that one holds as the truth, and in which one places confidence or identifies with. Core beliefs are imprinted, established or impressed 
firmly very early in the mind of the developing child. Cognitive-behavioural interventions are carried out through the examination of these imprints, proxies or impressions produced during the child's cognitive development and which were created by the circumstances surrounding the child's very early months and early years of life.

Schemas can be thought of as memories of the past, of what was/used to be, and such memories give valuable insights into one's early life experiences, emotions, behaviours, and also on disturbances caused by the interaction between one and one's environments over a long period of cognitive development. As internal representations of the world, of oneself, and of others, schemas or core beliefs are the roots of all the interpretations one makes about one's life experiences.

In order to study one's core beliefs, proxy data are collected from one's natural manifested thought contents [14]. Expressive arts such as drawing and applying painting to a surface activates streaming of cognitions which, if alert, one may detect, determine the existence, the presence of automatic thoughts, and then give an account or a representation of those flows in words. Such report in the immediate, the now present time and place will allow for an interpretation of one's core beliefs, because the information provided will reflect one's contents of thought.

\section{Participants}

\section{METHOD}

67 students attending their $2^{\text {nd }}$ cycle of studies in psychology (master's degree) participated in their very first session of training of personal and professional development of cognitivebehavioural clinical psychologists. There were nine males and 58 females thoroughly acquainted, through study, with the cognitive-behavioural model of learning.

\section{Materials and procedure}

The participants were first instructed on the goals intended to be attained for that training session, on how they were supposed to act (being alert to the task and at the same time quietly watching their streaming of thoughts without making judgements or replying to those thoughts, but just letting cognitions move through), and then each of the students was randomly presented with a sheet of paper containing outlines of images to be coloured.

Each sheet of paper contained different motifs, that is, differing contours of images to be coloured. The drawings of the outlines to be coloured pictured the natural physical world, plants, small and large animals, human figures, landscapes, boats, the human world, daily life, or the enchanted realm of fairies.

A large set of colouring pencils and crayons of various colours were available on a table and the students were allowed to choose freely in order to colour their respective contours.

The colouring part of the session lasted for about 40 minutes and then all the pencils, crayons, and the coloured images were collected. Then each of the students were presented with a lined sheet of paper and instructed to write down a report describing their conscious mental experiences during the colouring activity (an expressive arts activity [15]).

\section{RESULTS}

Data analysis followed a number of steps. The first step was the alert and careful reading of each of the participants' written report on his/her mental experiences with that expressive arts activity. Such reading allowed for a mentally perceptive and responsive grasp of the 
contents of each participant's cognitions or of the main thing they were reporting as their main cognitions during the expressive arts activity.

Along such awaken reading, a hypothesis then automatically emerged from this understanding of the nature of the information reported by the participants: Participants' composition of automatic thoughts during the expressive arts activity tended to provide information on their lives' past events, on their schedules, and on some of their inferences during the detection of those contents.

The second step was to extract and examine the common themes trapped in the contents reported [16]. Through this procedure, categories of themes could be obtained, providing information on the streaming of core beliefs during the expressive arts activity.

Three main categories of pouring of thoughts were evident in the participants' reported contents: a) The pouring of thoughts concerning the retrieval of Past Events; b) The pouring of thoughts concerning Schedules and Expectations; and c) The pouring of thoughts concerning Inferences.

\section{Thoughts concerning past events}

The category "Past Events" (representing 63.46\% of the categories distinguished), contained recollections about family and longing for family, and was subdivided into two subcategories: 1) Family and 2) Longing for Family.

The first subcategory (Family), representing 94.0\% of the contents in the category "Past Events", described life events mentioning "my mom and/or my daddy; my grandmother and/or my grandfather; my sister and/or my brother, my auntie and/or my uncle; my cousin, and my infancy (events from around six years of age to the beginning of adolescence)".

The second subcategory (Longing for family) described one's strong desire to get back to the past and live over some life experience with "my mom and/or my daddy; my grandmother and/or my grandfather; my sister and/or my brother, my auntie and/or my uncle; my cousin, and my infancy".

Some crystal clear examples for Category "Past Events" / Subcategory "Family" are: "...my mom telling me stories..."; "...my cousins and I decorating the trees..."; "...my father working at home..."; "...my father bringing home fruits and vegetables from the countryside..."; "...my brother used to paint..."; "...my grandmother's backyard..."; "...my mom had an old typewriter at home and I tried it once..."; "...my sisters and I used to listen to music together...”.

Some examples for Category "Past Events" / Subcategory "Longing for Family” are: “...get back to childhood and be with my family by the sea picking up shells..."; "...my countryside and when I was a child and watched cartoons..."; "...being a child again and having no responsibilities..."

The themes contained inside Category "Past Events" / Subcategories "Family" and "Longing for family" are exactly the same: "my mom, my daddy, my grandmother, my grandfather, my sister, my brother, my auntie, my uncle, my cousin, and my childhood".

\section{Thoughts concerning schedules and expectations}

The category "Schedules and Expectations" (representing 19.87\% of the differentiated categories) contained reminders for responsibilities, planned events, and anticipations. For 
instance: "...I must go to the supermarket..."; “...I have to make a phone call to my auntie...”; “...I won't be able to finish painting this image..."; "...next weekend I will be home with my mom..."; "...I have to pack to go home for the weekend with my family..."; "...who will I become?";

"...everything will come up as I want...".

The themes contained inside the category "Schedules and Expectations" still lean towards "my family members".

\section{Thoughts concerning inferences}

The category "Inferences" (representing 16.67\% of the categories distinguished), comprised some kind of discernment. For instance: "...I totally identify myself with this image..."; "...life is made out of memories..."; "...why such pouring out of old memories?"; "...I am a perfectionist..."; "...adults are difficult people..."; "...nothing is forever..."; "...I fabricated a story for this image..."; "...thoughts were flowing at a high-velocity..."; "...I allowed myself to follow those running automatic thoughts..."; "...It is difficult not to make judgments..."; “...cognitions pulled me in overmuch bringing on more cognitions..."

\section{DISCUSSION}

In order to study one's core beliefs, proxy data were collected from one's natural manifested thought contents. A hypothesis spouted from a first brisk glancing over the contents delivered by the participants in their written report of their conscious mental experience during the activity of expressive arts. Such hypothesis was corroborated after a detailed examination through a process of content analysis.

Every participants' cognitive contents depicted cognitions basically centred on one's life events from the past (recapitulation) and specifically with close family relatives, chiefly by blood (mother, father, siblings, grandparents, cousins, aunties, and uncles). From such level of cognitions (the more surface-level of automatic thoughts) the more root-like level of cognitive schemas (core beliefs) may be inferred [17].

Cognition, as the psychological result of one's perception, learning and thought, is conditioned by the past and, as such, one is permanently reprising or living one's past over and over again inside one's imagination through streaming of automatic thoughts. One ends up identifying oneself with those repetitive flows of memories producing an artificial notion of identity which very early in life began sculpting one's early core beliefs.

Thought seems to be a reaction to the movement of memory, emotion seems to be a reaction to the movement of thought, and behaviour seems to be a reaction to emotion. When one identifies oneself with thought, emotion arises, however thought may be just the flow of some unreal vague idea in which some confidence is placed and, even so, then any emotional reaction will feed that very thought and produce some more movement of memory.

Cores beliefs or unconscious presuppositions elicit streaming of cognitions that elicits emotional reactions that in its turn make one acts accordingly. That dynamic creates one's personal (inward and outward) reality. For instance, one of the participants reported noticing the thought "...when I was a child my teachers were always criticizing the way I coloured the drawings..." and the feeling "...I am troubled on the choice of colours..."

There clearly was an artificial notion of identity, a reality where "I, me, and mine" represented a person's core beliefs with all its consequences, misunderstandings, misinterpretations, divisions, and (inner and outer) conflicts. Nevertheless, according to palaeoclimatologists 
Bertelli, R. (2019). The Application of an Expressive Arts Activity for the very First Session of Training of Personal and Professional Development of Cognitive-Behavioural Clinical Psychologists: Cognitive Content as Proxy Data to Study Core Beliefs. Advances in Social Sciences Research Journal, 6(7) 599-605.

human activities have become a geological force and the astrobiologist Grinspoon goes further speaking of the coming of something of very great significance, that is, this geological force's self-awareness [1].

Considering results just presented, for such prediction (the coming of this geological force's self-awareness) to come true it would require from humankind a deep understanding of nature, including an extremely sharp and strongly felt self-understanding, and the transcendence of thought itself, thus, a subject beyond the scope of this article.

\section{CONCLUSION}

Automatic thoughts are reruns of past events and these reruns are often rebroadcast. These reruns contain scenes from the past whose main actors are one's self and stories, one's mother, one's father, one's siblings, one's grandparents, etc. These reruns point to the core beliefs that were fabricated by thought and conditioned by the past. Realising, being fully aware or cognizant that this is how the cognitive system works may prevent one from being carried away by automatic thoughts.

\section{References}

Grinspoon, D. (2019). Climate Catastrophes in the Solar System. In R. Pena dos Reis, M. H. Henriques, L. Oosterbeek, P. Rosina, E. I. Alves, G. G. Garcia, \& P. João (eds.), International Meeting on Paleoclimate: Change and Adaptation - book of abstracts (pp. 19). Mação: Série Area Domeniu, vol. 8, Instituto Terra e Memória - Centro de Geociências da Universidade de Coimbra. ISBN: 978-989-54041-5-5

Tolle, E. (2005). A New Earth - Awakening to Your Life's Purpose. Dutton/Penguin Group. ISBN: 0-452-28996-3

Lopez-Elorza, M., Muñoz-Garcia, M. B., Dublyansky, Y., Töchterle, P., Garay, P., Spötl, C., \& Martín-Chivelet, J. (2019). How can fossil water trapped in speleothems provide paleoclimate information? Insights from stable isotope analysis of fluid inclusions. In R. Pena dos Reis, M. H. Henriques, L. Oosterbeek, P. Rosina, E. I. Alves, G. G. Garcia, \& P. João (eds.), International Meeting on Paleoclimate: Change and Adaptation - book of abstracts (pp. 55). Mação: Série Area Domeniu, vol. 8, Instituto Terra e Memória - Centro de Geociências da Universidade de Coimbra. ISBN: 978-989-54041-5-5

Simões, J. C. (2019). The record of the Holocene environmental changes in the polar and mountain ice cores. In R. Pena dos Reis, M. H. Henriques, L. Oosterbeek, P. Rosina, E. I. Alves, G. G. Garcia, \& P. João (eds.), International Meeting on Paleoclimate: Change and Adaptation - book of abstracts (pp. 109). Mação: Série Area Domeniu, vol. 8, Instituto Terra e Memória - Centro de Geociências da Universidade de Coimbra. ISBN: 978-989-54041-5-5

Djindjian, F. (2019). Animal extinctions and climate change in the Quaternary period. In R. Pena dos Reis, M. H. Henriques, L. Oosterbeek, P. Rosina, E. I. Alves, G. G. Garcia, \& P. João (eds.), International Meeting on Paleoclimate: Change and Adaptation - book of abstracts (pp. 85). Mação: Série Area Domeniu, vol. 8, Instituto Terra e Memória Centro de Geociências da Universidade de Coimbra. ISBN: 978-989-54041-5-5

Neto de Carvalho, C., Figueiredo, S., Proença e Cunha, P., \& Belo, J. (2019). The sedimentary record of fossil elephants: The relevance of the Portuguese aeolianite archive and its environmental and paleoclimatic information of the Last Glacial Maximum. In R. Pena dos Reis, M. H. Henriques, L. Oosterbeek, P. Rosina, E. I. Alves, G. G. Garcia, \& P. João (eds.), International Meeting on Paleoclimate: Change and Adaptation - book of abstracts (pp. 105-106). Mação: Série Area Domeniu, vol. 8, Instituto Terra e Memória - Centro de Geociências da Universidade de Coimbra. ISBN: 978-989-54041-5-5

Nash, G. (2019). A tale of two lost villages: Medieval plague or minute changes in climate? In R. Pena dos Reis, M. H. Henriques, L. Oosterbeek, P. Rosina, E. I. Alves, G. G. Garcia, \& P. João (eds.), International Meeting on Paleoclimate: Change and Adaptation - book of abstracts (pp. 89). Mação: Série Area Domeniu, vol. 8, Instituto Terra e Memória - Centro de Geociências da Universidade de Coimbra. ISBN: 978-989-54041-5-5

Owczarek, P. \& Opala-Owczarek, M. (2019). Environmentally induced rise and fall of societies in Central Asia in the first millennium AD. In R. Pena dos Reis, M. H. Henriques, L. Oosterbeek, P. Rosina, E. I. Alves, G. G. Garcia, \& P. João (eds.), International Meeting on Paleoclimate: Change and Adaptation - book of abstracts (pp. 127-128). Mação: Série Area Domeniu, vol. 8, Instituto Terra e Memória - Centro de Geociências da Universidade de Coimbra. ISBN: 978-989-54041-5-5 
Opala-Owczarek, M., Owczarek, P., Lupikasza, E., \& Niedźwiedź, T. (2019). Megadroughts and political changes in western Central Asia and Mongolian Plateau over the past 1000 years as revealed by three rings. In R. Pena dos Reis, M. H. Henriques, L. Oosterbeek, P. Rosina, E. I. Alves, G. G. Garcia, \& P. João (eds.), International Meeting on Paleoclimate: Change and Adaptation - book of abstracts (pp. 131-132). Mação: Série Area Domeniu, vol. 8, Instituto Terra e Memória - Centro de Geociências da Universidade de Coimbra. ISBN: 978-989-54041-5-5

Bertelli, R. (2019a). Does the Cognitive-Behavioural Model of Learning share features of Buddha's and Krishnamurti's Teachings? Using the Concept of Automatic Maladaptive Thoughts as an Example. Advances in Social Sciences Research Journal, 6(2), 475-480. doi: 10.14738/assrj.62.6222

Bertelli, R. (2019b). Cognitive-behavioural clinical psychologists in training of personal and professional development by means of expressive arts activities manifest repetitive flows of conditioned negative automatic thoughts. Journal of Arts \& Humanities, 8(5), 42-48. doi: https://www.theartsjournal.org/index.php/site/article/view/1646/748

Aubert, M., Setiawan, P., Oktaviana, A. A., Brumm, A., Sulistyarto, P. H., Saptomo, E. W.... Brand, H. E. A. (2018). Palaeolithic cave art in Borneo. Nature, 564, 254-257. doi: https://doi.org/10.1038/s41586-018-0679-9

Sigari, D. (2013). Palaeolithic rock art in Gobustan, Azerbaijan. The study case of rock 44 of Böyük Daş, Gobustan. Journal of Iranian Archaeology, 4, 15-22. ISBN: 978-600-04-0520-5

Ginsburg, H. P., \& Opper, S. (1988). Piaget's Theory of Intellectual Development. 3rd ed. Englewood Cliffs, NJ: Prentice-Hall International, Inc.

Keller-Dupree, E. A. \& Perryman, K. L. (2013). The effects of an expressive arts therapy group on female counsellors-in-training: A qualitative study. Journal of Poetry Therapy, 26(4), 223-235. doi: 10.1080/08893675.2013.849041

Bardin, L. (1977). L'Analyse de Contenu. Paris: Presses Universitaires de France.

Beck, A. T., \& Dozois, D. J. A. (2011). Cognitive therapy: Current status and future directions. Annual Review of Medicine, 62, 397-409. doi: 10.1146/annurev-med-052209-100032 